\title{
The Brain Metabolic Patterns of Clozapine- and Fluphenazine-Treated Female Patients with Schizophrenia: Evidence of a Sex Effect
}

Robert M. Cohen, Ph.D., M.D., Thomas E. Nordahl, Ph.D., M.D., William E. Semple, Ph.D., and David Pickar, M.D.

The regional cerebral glucose metabolic rates of clozapinetreated and fluphenazine-treated women with schizophrenia and normal controls were obtained by positron emission tomography (PET) using $\left[{ }^{18} F\right]$-2-fluoro-2-deoxy-D-glucose (FDG) as the tracer. The regional metabolic patterns were compared to each other and to the changes previously observed in men. In women, as in men, both clozapine- and fluphenazine-treatment were associated with lower metabolism in the superior prefrontal cortex and higher metabolism in the medial temporal lobe. In both men and women, clozapine treatment led to a greater lowering of inferior prefrontal cortex activity than fluphenazine, which was statistically significant in the larger male cohort. Fluphenazine led to higher metabolic rates in the lateral temporal lobe than clozapine did, but the differences between the two neuroleptics were not statistically significant in either group. The greatest differences in the female as compared to the male responses to fluphenazine and clozapine were in the cingulate and striatum. As compared to controls, the cingulate metabolic rates of women were reduced by $9.1 \%$ and $11.4 \%$ on clozapine and fluphenazine, respectively; whereas, men have a statistically nonsignificant reduction of $0.1 \%$ with clozapine and a $3.2 \%$ increase with fluphenazine. In men, fluphenazine was associated with a much greater elevation in basal ganglia metabolic rates than was clozapine, $23.5 \%$ as compared to $3.75 \%$; whereas, in women, basal ganglia metabolic rates are nearly equally increased by fluphenazine $(21.6 \%)$ and clozapine (15.1\%). [Neuropsychopharmacology 21:632-640, 1999] Published by Elsevier Science Inc.
KEY WORDS: Striatum; Cingulate; Deoxyglucose; Cerebral metabolic rates; Positron emission tomography; Neuroleptics

In reviewing the literature, Goldstein (1995), concluded that, as compared to women, men with schizophrenia

From the Laboratory of Cerebral Metabolism (RMC, DP), National Institute of Mental Health and Experimental Therapeutics Branch, National Institute of Mental Health, Bethesda, Maryland; University of California Medical Center (TEN), Davis, Napa State Hospital, Napa, California; and the Lawrence Berkeley National Laboratory, Berkeley, California; Case Western Reserve University and the VAMC (WES), Cleveland, Ohio.

Address correspondence to: Robert M. Cohen, Ph.D., M.D., Clinical Brain Imaging Section, LCM, NIH, Bldg. 36, Room 1A05, 36 Convent Dr. MSC 4030, Bethesda, MD, 20892-4030.

Received November 17, 1998; revised April 30, 1999; accepted May 20, 1999. have an earlier age of onset, have a poorer premorbid history, and express symptoms differentially. Women tend to have a better prognosis, including fewer hospitalizations, shorter lengths of hospitalization, less psychopathology during remission, and superior social adjustment than men do. To account for the apparent better treatment response of women early in the disorder, a number of possibilities have been suggested (Seeman 1995), including a differential gender effect on the number and severity of prenatal complications, the age of onset of the disorder, the pretreatment duration of symptoms, as well as the possibility that neuroleptic treatment, itself, might act differentially in the sexes.

For the most part, neuroimaging studies of neuroleptics have not been analyzed with respect to sex. Specifically, with respect to positron emission tomography 
(PET) studies, this absence is at least partially attributable to the relatively small number of subjects scanned in each study. These studies (Cohen et al. 1988b, 1997) established that, as compared to healthy subjects, our male patients treated with typical neuroleptics have a broad decrease in normalized, frontal cortex metabolism with a greater effect on the middle-superior prefrontal region than the inferior prefrontal, and an increase in normalized temporal lobe and subcortical metabolism. The one study of the atypical clozapine, when compared to the typical neuroleptic fluphenazine (Cohen et al. 1997) suggested that clozapine engendered a greater reduction in the inferior prefrontal cortex than fluphenazine, but did not seem to increase lateral temporal lobe and had a much smaller effect on normalized metabolic rates in the basal ganglia and thalamus.

However, the size of the regional metabolic changes we observed with PET in male schizophrenic patients treated with typical neuroleptics, and the reliability of these changes (Cohen et al. 1988b, 1997), encouraged us to compare the metabolic brain patterns of women who were treated with the typical neuroleptic fluphenazine and the atypical neuroleptic clozapine to normal controls.

These findings could then be compared to those found in men. Regions where the effects of clozapine and fluphenazine treatment are the same in men and women are more likely to represent the efficacy targets of antipsychotic drugs. Regions where men and women differ are candidates for areas responsible for any sex differences either in symptom response or sensitivity to side effects.

\section{MATERIALS AND METHODS}

All of the female and male schizophrenic patients scanned while receiving fluphenazine or clozapine treatment were part of previous PET studies (Cohen et al. 1997, 1998); with the exception of the female patients and six additional male clozapine-treated patients. Because of the greater number of male patients scanned, the initial analysis and publication of the patient data was in males only, and with only the first 11 clozapinetreated patients. This number was deemed sufficient for the comparisons of the regional metabolic rates of male clozapine-treated schizophrenic patients to healthy men and to male fluphenazine-treated patients, which in that particular arm of our study was 10 . We had previously been able to observe robust effects of neuroleptics with fewer than 10 patients. However, when we began our analysis of the female data, we increased the number of clozapine-treated male patients analyzed for the purpose of increasing the statistical power of malefemale comparisons.
As described in these papers, the diagnosis of schizophrenia was made on the basis of the evaluation of two psychiatrists. All patients were given a modified SADS and met DSM III-R criteria (APA 1987). Patients were excluded if a significant medical or neurological problem was present. The methods of screening and exclusion criteria for comparison subjects have also been reported (Cohen et al. 1997). Size and ages of groups were as follows: clozapine-treated patients, 17 males: $35.4 \pm$ 7.7 years and seven females: $28.2 \pm 6.4$ years; fluphenazine-treated patients, 22 males: $31.8 \pm 6.2$ and six females $27.5 \pm 5.0$; comparison subjects, 41 males: $31.4 \pm$ 8.6 and 40 females: $34.7 \pm 11.9$. The only differences in ages of statistical significance as assessed by Student's $t$-tests were that between the male and female clozapine-treated patients.

Patient symptoms during the week of scan and during the last week of placebo before receiving neuroleptic treatment were measured using the Bunney-Hamburg Rating Scale for psychosis (BHRS-P) (Bunney and Hamburg 1963) and the Brief Psychiatric Rating Scale (BPRS) (Overall and Gorham 1961). A detailed description of the patient populations and their clinical and biologic responses to fluphenazine and clozapine treatment has been reported (Pinals et al. 1996; Pickar et al. 1992). All patients were residing on a research unit at the NIH at the time of scan. All patients and normal controls gave informed consent before their scans.

\section{PET Scan Procedure}

Subjects, with eyes patched, began their auditory discrimination task several minutes before the injection of 4 to $5 \mathrm{mCi}$ of $\left[{ }^{18} \mathrm{~F}\right] \mathrm{FDG}$ and completed the task $30 \mathrm{~min}-$ utes after injection. The auditory discrimination task, in which subjects must identify one of three auditory tones, has been described in detail elsewhere (Cohen et al. 1988a). Scanning, beginning $30 \mathrm{~min}$ after isotope injection, was performed on a Scanditronix (Essex, MA) PET scanner with a 5- to 6-mm full-width-half-maximum in-plane resolution and a $z$-axis resolution of 11.8 $\mathrm{mm}$. A transmission scan was used to calculate attenuation, and the tracer input curve was calculated from blood samples obtained from the radial artery. Four sets of seven planes were obtained for each subject starting at $5 \mathrm{~mm}$ above the plane parallel to the canthomeatal line (CM). The interslice interval was approximately $3.5 \mathrm{~mm}$.

\section{Data Analysis}

Raw pixel values were converted to glucose metabolic rates in $\mu$ moles of glucose per $100 \mathrm{~g}$ of tissue per minute by means of previously reported kinetic constants 
(Brooks 1982; Phelps et al. 1979; Sokoloff et al. 1977). To extract regional glucose metabolic rates, 60 rectangular boxes were located in five standard planes (plane A, 94 $\mathrm{mm}$ above $\mathrm{CM}$ line; plane $\mathrm{B}, 81 \mathrm{~mm}$ above $\mathrm{CM}$ line; plane $\mathrm{C}, 67 \mathrm{~mm}$ above $\mathrm{CM}$ line; plane $\mathrm{D}, 53 \mathrm{~mm}$ above $\mathrm{CM}$ line; plane $\mathrm{E}, 40 \mathrm{~mm}$ above $\mathrm{CM}$ line) chosen from one of the four seven-plane scan sets (Cohen et al. 1988a; Cohen et al. 1992; Semple et al. 1993). Anatomical structures were judged as contained within these regions according to the human brain atlas of Matsui and Hirano (1978). Schematic representations of the regions of interest (ROIs) in sagittal and coronal planes have been published (Cohen et al. 1998; Andreason et al. 1994). The regional metabolic rates reported are normalized or relative regional metabolic rates calculated by dividing the absolute regional metabolic rate by the global gray glucose metabolic rate. The global gray glucose metabolic rate was determined as the average of the gray matter-rich areas of the cortex sampled in planes B to E (an adequate match for plane A could not be found in a few subjects). Normalization eliminates the effects of global gray glucose metabolic rates on tests of the localized; that is, regional effects of neuroleptic drug treatment, while maximizing the power and reliability of these comparisons. The importance of normalization for the adequate examination of regional changes is suggested by the very high correlations between regional absolute metabolic rates and global gray glucose metabolic rates. For example, in the 41 female healthy subjects, the correlation between global gray metabolic rates and the six large ROIs were superior prefrontal cortex, $\mathrm{r}=.98$, inferior prefrontal cortex, $\mathrm{r}=$ .97 , parietal-occipital cortex, $\mathrm{r}=.96$, lateral temporal cortex, $r=.96$, and subcortex, $r=.91$. Thus, even in the subcortex, the region with the lowest correlation, less than $18 \%$ of the variation in absolute metabolic rate is attributable to localized error and regional variation in absolute metabolic rate.

\section{Statistical Analysis}

Previous studies (Cohen et al. 1988b, 1997) established that typical neuroleptics, in men, induce a broad decrease in normalized, middle to superior greater than inferior frontal cortex metabolism and an increase in normalized temporal lobe and subcortical metabolism. As was our approach in that work, the female data were first assessed with a multivariate analysis of variance (MANOVA) to reduce the possibility of a type I error. As described (Cohen et al. 1997), the original 60 extracted ROIs were combined into the six larger regions of superior prefrontal cortex (planes B and C), inferior prefrontal cortex (planes D and E), parietal-occipital cortex, lateral temporal cortex, limbic cortex (cingulate + medial temporal cortex), and subcortex (thalamus + basal ganglia) (The convention of capitalizing the first letters of the names of the larger ROIs will distinguish them from the names of the smaller ROIs conveyed in lower case. In previous papers, as in this paper, the medial temporal cortex region is also referred to as the hippocampus, because the ROI includes both the hippocampal and parahippocampal regions.) This allowed for a single multivariate test, the Hotelling's $\mathrm{T}^{2}$, to evaluate whether there were significant localized differences between each neuroleptic-treated female patient group and the comparison control group.

Any apparent differences between the results of the multivariate analysis in women and the previous multivariate analysis in men received additional examination through analyses of variance (ANOVA). The ANOVAs were initially performed using normal controls and treated patients as the two levels of factor one (DRUG, referred to as CLOZAPINE, when analyzing data from clozapine-treated patients, and FLUPHENAZINE when referring to fluphenazine-treated patients), and men and women as the two levels of factor two (SEX). (The convention of capitalizing statistical factors is adhered to throughout the manuscript.) When significance was observed in a large ROI consisting of many smaller ROIs, a hierarchical analysis followed. Subgrouped smaller ROIs comprised the within- subjects factor REGION in a three-way ANOVA where DRUG (CLOZAPINE or FLUPHENAZINE) and SEX were the two between-subjects factors. In the two-way analyses, finding an interaction between DRUG and SEX, and in the three-way analyses, between DRUG, SEX, and REGION established a differential affect in women as compared to men. When appropriate, univariate tests using the least significant differences method (LSD) were used for the final determination of localized differences.

Our choice of the hierarchical- and hypothesisdriven analysis described above, although an alternative to correcting for multiple comparisons to help protect against a type I error, does not take the place of using Bonferroni corrections. Although the likelihood of a type I error having occurred in the comparisons of the larger regions would be predictably small, some of the most localized regional differences between male and female patients receiving neuroleptics may have a somewhat inflated $p$ value, and therefore, where the significance level is $>.001$, could have resulted from a type I error. It is important to note that the Bonferroni correction is only a temporary substitute for replication. Thus, in the instance where statistical significance is observed for a sex effect in the same region in response to both clozapine and fluphenazine, the absence of a Bonferroni correction is less relevant. It is only in the instance of a sex difference observed in response to either clozapine or fluphenazine, but not the other, that the issue becomes important. However, because of the small numbers of female patients, we still opted to forego the use of the Bonferroni correction. Our preference was to 
run the risk of generating a testable hypothesis that, in the future, might prove to be false, then to reject the possibility of sex differences in neuroleptic effects and, as a result, potentially inhibit the examination and design of studies to evaluate this possibility.

\section{RESULTS}

Table 1 illustrates the similarity between the female and male patients with respect to state and treatment variables. Statistically significant differences were not observed among any of these variables by Student's $t$-test. Table 2 summarizes the MANOVA data on the comparisons of the clozapine- and the fluphenazine-treated patients with the female control group. The highly significant Hotelling's $\mathrm{T}^{2}$ is consistent with the large differences previously observed with neuroleptic-treated male patients and reproduced in Table 2 for comparison purposes.

\section{Similarities Between Male and Female Neuroleptic Responses (Table 2)}

With respect to fluphenazine, the female patients, as did the previously reported male patients, had decreased normalized metabolic rates in the Superior Prefrontal Cortex and increased metabolic rates in the Lateral Temporal Cortex and the Subcortex when each was compared to same sex controls. Inferior Prefrontal Cortex metabolic rate decreases were smaller and not of statistical significance. With respect to clozapine, both females and males had lower normalized Superior Prefrontal Cortex and Inferior Prefrontal Cortex metabolic rates and increased Parietal-Occipital Cortex metabolic rates.

\section{Differences Between Male and Female Neuroleptic Responses}

Based on apparent sex differences in the response to fluphenazine and clozapine in the Limbic Cortex and in response to clozapine in the Subcortex (Table 2), a formal statistical analysis of these differences were undertaken to establish their significance and further localization.

Limbic Regions (Table 3). The effects of clozapine and sex on the smaller regions of left and right medial temporal cortex and cingulate, the regions comprising the Limbic Cortex, were examined with two-way ANOVAs. A significant interaction was observed between CLOZAPINE and SEX for cingulate metabolism $(\mathrm{F}[1,101]=3.9, p=.05)$. Whereas clozapine reduced glucose metabolic rate in the cingulate by $9.1 \%$ in women, there was only a $0.1 \%$ reduction in men. A main effect for CLOZAPINE (F[1,101] $=23.0, p=5.7 \times$ $\left.10^{-6}\right)$, but not for SEX $(\mathrm{F}[1,101]=0.03, p=\mathrm{NS})$, and not for an interaction between SEX and CLOZAPINE $(\mathrm{F}[1,101]=0.13, p=\mathrm{NS})$ was found for medial temporal cortex ROI (hippocampus) metabolism. Clozapine increased the normalized metabolic rates of the hippocampal region in both the female and male patients.

FLUPHENAZINE was also found to have a significant interaction with SEX with respect to cingulate metabolism $(\mathrm{F}[1,105]=9.51, p<.003)$, but not with respect to the medial temporal cortex $(\mathrm{F}[1,105]=1.9, p=$ NS). Cingulate metabolism was $11.4 \%$ lower in female patients receiving fluphenazine than in normal women; whereas, the cingulate regions of male patients receiving fluphenazine was $3.2 \%$ higher than normal men. The medial temporal cortex demonstrated a main affect for FLUPHENAZINE $(F[1,105]=18.2, p<.00004)$, because both male and female patients treated with fluphenazine had higher hippocampal metabolic rates than normal men and women, respectively.

Subcortex (Table 3). Because the Subcortex consists of eight regions, the left and right thalamus, caudate, anterior and posterior putamen regions, we performed a hierarchical analysis of the interaction of CLOZAPINE and SEX, beginning with the complete set of ROIs comprising the Subcortex region. A significant SEX $\times$ CLOZAPINE $\times$ REGION interaction was observed in

Table 1. Symptomatology and Neuroleptic Doses of Female and Male Patients

\begin{tabular}{|c|c|c|c|c|c|c|}
\hline & \multicolumn{3}{|c|}{ Clozapine } & \multicolumn{3}{|c|}{ Fluphenazine } \\
\hline & Females $(n=7)$ & Males $(n=17)$ & $p$ Value & Females $(n=6)$ & Males $(n=22)$ & $p$ Value \\
\hline Dose (mg/day) & $426.1 \pm 134.1$ & $425.2 \pm 197.0$ & $>.99$ & $28.2 \pm 10.0$ & $22.9 \pm 11.9$ & $>.32$ \\
\hline \multicolumn{7}{|l|}{$\begin{array}{l}\text { Ratings } \\
\text { (at time of scan) }\end{array}$} \\
\hline BHRS-P & $6.1 \pm 2.0$ & $5.5 \pm 1.5$ & $>.42$ & $6.3 \pm 2.9$ & $5.8 \pm 1.4$ & $>.54$ \\
\hline BPRS & $54.6 \pm 11.3$ & $51.2 \pm 11.4$ & $>.51$ & $56.0 \pm 19.5$ & $52.8 \pm 11.9$ & $>.61$ \\
\hline SANS & $50.1 \pm 13.7$ & $57.5 \pm 16.4$ & $>.29$ & $58.2 \pm 31.3$ & $56.6 \pm 18.2$ & $>.87$ \\
\hline \multicolumn{7}{|l|}{$\%$ Response to drug } \\
\hline BHRS-P & $22.7 \pm 26.0$ & $26.6 \pm 27.5$ & $>.75$ & $23.8 \pm 18.6$ & $23.8 \pm 27.1$ & $>.99$ \\
\hline BPRS & $22.6 \pm 22.0$ & $20.4 \pm 20.4$ & $>.81$ & $17.0 \pm 24.7$ & $17.0 \pm 19.5$ & $>.99$ \\
\hline SANS & $18.0 \pm 35.4$ & $17.0 \pm 22.9$ & $>.93$ & $13.4 \pm 24.6$ & $13.4 \pm 23.7$ & $>.99$ \\
\hline
\end{tabular}


the Subcortex $(\mathrm{F}[1,101]=4.98, p<.03)$. Subgrouping the regions comprising the subcortex into striatum and thalamus, a significant SEX $\times$ DRUG $\times$ REGION interaction was observed for those ROIs comprising the striatum $(\mathrm{F}[1,101]=7.5, p<.008)$, but not for those comprising the thalamus $(\mathrm{F}[1,101]=0.4, p=\mathrm{NS})$.

Within the striatum, a significant two-way interaction (CLOZAPINE $\times$ SEX) was observed for the ROIs comprising the putamen $(\mathrm{F}[1,101]=9.04, p<.004)$, but not for those of the caudate $(\mathrm{F}[1,101]=2.8, p<.1)$. Within the putamen, there was a three-way interaction between REGIONS (left and right anterior and posterior putamen regions), CLOZAPINE and SEX $(\mathrm{F}[3,303]=$ $3.77, p<.02)$. Examining each of these regions, in turn, a significant interaction between CLOZAPINE and SEX was found for the anterior putamen $(\mathrm{F}[1,101]=6.12$, $p<.02)$, and for the posterior putamen $(\mathrm{F}[1,101]=5.15$, $p<.03)$. Within the anterior and posterior putamen, there were significant CLOZAPINE and SEX interactions with respect to the left anterior $(\mathrm{F}[1,101]=13.89$, $p<.0004)$ and left posterior regions $(\mathrm{F}[1,101]=11.4, p=$ $.001)$ but not the right anterior $(\mathrm{F}[1,101]=1.85, p<.18)$ and posterior $(\mathrm{F}[1,101]=1.01, p=\mathrm{NS})$ regions. These interactions were the result of clozapine increasing the metabolic rates of basal ganglia structures in the female patients to a much greater degree than in the male pa- tients. This was most prominent in the left anterior and posterior putamen regions, where there was minimal effect in the male patients, but to some extent, also occurred in the right anterior and posterior putamen and the left and right caudate.

As expected, based on the multivariate analysis of the fluphenazine data, there was no interaction between FLUPHENAZINE and SEX $(\mathrm{F}[1,105]=.88, p=$ NS) with respect to the Subcortex, only a main effect for FLUPHENAZINE $(\mathrm{F}[1,105]=54.0, p<10-6)$. Fluphenazine increased the normalized metabolic rates of all subcortical structures in both the female and male patients. Thus, no further statistical analysis was performed with respect to regional variation within the subcortex.

\section{DISCUSSION}

The findings in women lend weight to the suggestion, generated on the basis of the data in men, that clozapine and fluphenazine have similar effects on the functional activities of many brain regions and that treatment with neuroleptics primarily leads to "compensation" and "adaptation" rather than normalization of functional brain activities (Cohen et al. 1997). The compensation

Table 2. Multivariate Analysis of Normalized Metabolic Rates for Clozapine- and Fluphenazine- Treated Patients Compared to Normal Controls

\begin{tabular}{|c|c|c|c|c|c|c|c|c|c|c|}
\hline \multirow[b]{4}{*}{ Brain Region } & \multicolumn{4}{|c|}{ Clozapine Group } & \multicolumn{4}{|c|}{ Fluphenzine Group } & & \\
\hline & \multicolumn{4}{|c|}{ Hotelling's $\mathrm{T}^{* * 2}$} & \multicolumn{4}{|c|}{ Hotelling's $\mathrm{T}^{* * 2}$} & & \\
\hline & \multicolumn{4}{|c|}{$\begin{array}{l}\text { Female } \mathrm{T}^{* *} 2=45.9, \mathrm{~F}(6,36)=6.72, p<.0001 \\
\text { Male } \mathrm{T}^{* *} 2=51.6, \mathrm{~F}(6,51)=7.84, p<.00001\end{array}$} & \multicolumn{4}{|c|}{$\begin{array}{l}\mathrm{T}^{* * 2}=42.9, \mathrm{~F}(6,36)=6.27, p<.0002 \\
\mathrm{~T}^{* * 2}=75.8, \mathrm{~F}(6,54)=11.56, p<10^{* *}-6\end{array}$} & \multicolumn{2}{|c|}{$\begin{array}{l}\text { Control } \\
\text { Group }\end{array}$} \\
\hline & Mean & (SD) & $p$ Value & (\%) Change & Mean & (SD) & $p$ Value & (\%) Change & Mean & (SD) \\
\hline \multicolumn{11}{|c|}{ Superior Prefrontal Cortex } \\
\hline Female & 1.029 & $(.029)$ & .0003 & -4.4 & 1.024 & $(.018)$ & .00017 & -4.9 & 1.077 & $(.030)$ \\
\hline Male & 1.042 & $(.044)$ & .007 & -2.6 & 1.028 & $(.043)$ & $1.9 \mathrm{E}-05$ & -3.9 & 1.069 & $(.028)$ \\
\hline \multicolumn{11}{|c|}{ Inferior Prefrontal Cortex } \\
\hline Female & 0.974 & $(.039)$ & .0002 & -5.4 & 1.007 & $(.053)$ & .16 & -2.1 & 1.029 & $(.033)$ \\
\hline Male & 0.960 & $(.033)$ & $6.8 \mathrm{E}-06$ & -4.8 & 0.990 & $(.044)$ & .096 & -1.6 & 1.006 & $(.032)$ \\
\hline \multicolumn{11}{|c|}{ Parietal-Occipital Cortex } \\
\hline Female & 1.035 & $(.040)$ & .016 & 3.3 & 1.009 & $(.044)$ & .63 & 0.7 & 1.002 & $(.028)$ \\
\hline Male & 1.037 & $(.047)$ & .013 & 2.7 & 1.034 & $(.038)$ & .0085 & 2.5 & 1.009 & $(.033)$ \\
\hline \multicolumn{11}{|c|}{ Lateral Temporal Cortex } \\
\hline Female & 0.980 & $(.044)$ & .20 & 2.1 & 1.001 & $(.039)$ & .016 & 4.2 & 0.960 & $(.037)$ \\
\hline Male & 0.960 & $(.046)$ & .55 & -0.7 & 1.000 & $(.046)$ & .0034 & 3.4 & 0.967 & $(.038)$ \\
\hline \multicolumn{11}{|l|}{ Limbic Cortex } \\
\hline Female & 0.889 & $(.070)$ & .63 & -1.4 & 0.864 & $(.063)$ & .18 & -4.2 & 0.902 & $(.063)$ \\
\hline Male & 0.902 & $(.051)$ & .03 & 3.3 & 0.932 & $(.064)$ & $5.9 \mathrm{E}-05$ & 6.8 & 0.873 & $(.044)$ \\
\hline \multicolumn{11}{|l|}{ Subcortex } \\
\hline Female & 1.111 & $(.104)$ & .0006 & 10.3 & 1.146 & $(.102)$ & $2.3 \mathrm{E}-05$ & 13.7 & 1.007 & $(.061)$ \\
\hline Male & 1.027 & $(.085)$ & .31 & 2.2 & 1.183 & $(.127)$ & $1.4 \mathrm{E}-09$ & 17.8 & 1.005 & (.073) \\
\hline
\end{tabular}

Means of normalized metabolic rates are listed with standard deviation in parentheses for all six of the large ROIs. The statistical significance of differences between clozapine-treated (CLOZ) patients and fluphenazine-treated (FLU) patients and their same sex comparison subjects (NC) were determined on the basis of Hotelling's T ${ }^{2}$ tests. Percentage differences (\% Diff) for CLOZ and FLU are calculated as (CLOZ-NC) $\times 100 / N C$ and (FLUNC) $\times 100 / N C$, respectively. All calculations were performed with CSS-Statistica@. 
Table 3. Univariate, LSD comparisons of Normalized Metabolic Rates for Clozapine- and Fluphenazine- Treated Patients and Normal Controls: Means (Standard Deviations)

\begin{tabular}{|c|c|c|c|c|c|c|c|c|c|c|c|c|c|}
\hline & \multirow{2}{*}{\multicolumn{3}{|c|}{ CLOZ Group }} & \multirow{2}{*}{\multicolumn{3}{|c|}{ FLU Group }} & \multirow{2}{*}{\multicolumn{2}{|c|}{$\begin{array}{l}\text { Control } \\
\text { Group }\end{array}$}} & \multicolumn{5}{|c|}{$p$ values (LSD) } \\
\hline & & & & & & & & & \multicolumn{3}{|c|}{ F vs. $M$} & \multirow[b]{2}{*}{$\begin{array}{c}\text { CLOZ } \\
\text { vs. NC }\end{array}$} & \multirow[b]{2}{*}{$\begin{array}{c}\text { FLU } \\
\text { vs. NC }\end{array}$} \\
\hline & Mean & (SD) & $\begin{array}{c}(\%) \\
\text { Change }\end{array}$ & Mean & (SD) & $\begin{array}{c}(\%) \\
\text { Change }\end{array}$ & Mean & (SD) & CLOZ & FLU & NC & & \\
\hline \multicolumn{14}{|l|}{$\begin{array}{l}\text { Limbic cortex } \\
\text { cingulate }\end{array}$} \\
\hline Female & 0.954 & $(.101)$ & -9.1 & 0.929 & $(.122)$ & -11.4 & 1.049 & $(.110)$ & \multirow[t]{2}{*}{ ns } & \multirow[t]{2}{*}{0.04} & \multirow[t]{2}{*}{0.006} & 0.02 & 0.005 \\
\hline Male & 0.988 & $(.098)$ & -0.1 & 1.021 & (.097) & 3.2 & 0.989 & $(.075)$ & & & & ns & ns \\
\hline \multicolumn{14}{|c|}{ L hippocampus } \\
\hline Female & 0.827 & $(.063)$ & 8.0 & 0.832 & $(.042)$ & 8.7 & 0.766 & $(.056)$ & \multirow[t]{2}{*}{ ns } & \multirow[t]{2}{*}{ ns } & \multirow[t]{2}{*}{ ns } & 0.001 & 0.0006 \\
\hline Male & 0.816 & $(.093)$ & 8.5 & 0.840 & $(.107)$ & 11.7 & 0.752 & $(.046)$ & & & & $3.0 \mathrm{E}-06$ & $<1 \mathrm{E}-06$ \\
\hline \multicolumn{14}{|c|}{$\mathrm{R}$ hippocampus } \\
\hline Female & 0.821 & $(.090)$ & 10.6 & 0.764 & $(.057)$ & 3.0 & 0.742 & $(.060)$ & \multirow[t]{2}{*}{ ns } & \multirow[t]{2}{*}{$6.0 \mathrm{E}-05$} & \multirow[t]{2}{*}{0.05} & .00042 & ns \\
\hline Male & 0.817 & $(.081)$ & 7.4 & 0.846 & $(.098)$ & 11.2 & 0.761 & $(.058)$ & & & & $3.0 \mathrm{E}-05$ & $<1 \mathrm{E}-06$ \\
\hline \multicolumn{14}{|l|}{ Striatum } \\
\hline \multicolumn{14}{|l|}{ L caudate } \\
\hline Female & 1.105 & $(.098)$ & 4.0 & 1.153 & $(.140)$ & 8.6 & 1.062 & $(.107)$ & .001 & ns & 0.003 & ns & .0055 \\
\hline Male & 0.997 & $(.102)$ & -1.7 & 1.160 & $(.155)$ & 14.3 & 1.015 & $(.098)$ & & & & ns & $<1 \mathrm{E}-06$ \\
\hline $\mathrm{R}$ caudate & & & & & & & & & & & & & \\
\hline Female & 1.054 & $(.102)$ & 5.5 & 1.049 & $(.101)$ & 4.9 & 1.000 & $(.097)$ & .02 & 0.0002 & ns & 0.06 & ns \\
\hline Male & 0.982 & (.113) & -3.2 & 1.178 & (.182) & 16.1 & 1.014 & $(.095)$ & & & & ns & $<1 \mathrm{E}-06$ \\
\hline $\mathrm{L}$ ant put & & & & & & & & & & & & & \\
\hline Female & 1.273 & $(.210)$ & 22.0 & 1.298 & $(.243)$ & 24.4 & 1.043 & $(.111)$ & $2.0 \mathrm{E}-05$ & ns & 0.002 & $<1 \mathrm{E}-06$ & $<1 \mathrm{E}-06$ \\
\hline Male & 1.110 & $(.083)$ & 0.6 & 1.344 & $(.280)$ & 21.7 & 1.104 & $(.121)$ & & & & ns & $<1 \mathrm{E}-06$ \\
\hline $\mathrm{R}$ ant puta & & & & & & & & & & & & & \\
\hline Female & 1.241 & $(.189)$ & 19.8 & 1.289 & $(.185)$ & 24.4 & 1.036 & $(.115)$ & 0.008 & ns & ns & $<1 \mathrm{E}-06$ & $<1 \mathrm{E}-06$ \\
\hline Male & 1.143 & $(.128)$ & 12.2 & 1.258 & $(.213)$ & 23.5 & 1.019 & $(.105)$ & & & & $<1 \mathrm{E}-06$ & $<1 \mathrm{E}-06$ \\
\hline L post p & & & & & & & & & & & & & \\
\hline Female & 1.189 & $(.156)$ & 23.0 & 1.281 & $(.214)$ & 32.5 & 0.966 & $(.078)$ & $3.0 \mathrm{E}-06$ & ns & ns & $<1 \mathrm{E}-06$ & $<1 \mathrm{E}-06$ \\
\hline Male & 1.023 & (.139) & 4.8 & 1.319 & $(.240)$ & 35.1 & 0.977 & $(.100)$ & & & & 0.03 & $<1 \mathrm{E}-06$ \\
\hline $\mathrm{R}$ post pu & & & & & & & & & & & & & \\
\hline Female & 1.078 & $(.229)$ & 16.1 & 1.250 & $(.215)$ & 34.7 & 0.928 & $(.073)$ & ns & ns & 0.06 & $<4 \mathrm{E}-06$ & $<1 \mathrm{E}-06$ \\
\hline Male & 1.055 & (.146) & 9.8 & 1.261 & (.188) & 31.3 & 0.961 & $(.095)$ & & & & $3.0 \mathrm{E}-05$ & $<1 \mathrm{E}-06$ \\
\hline
\end{tabular}

Means of normalized metabolic rates are listed with standard deviations in parentheses for the small ROIs comprising the two larger ROIs, limbic cortex and striatum, for the clozapine-treated (CLOZ) female $(n=7)$ and male $(n=17)$ patients, the fluphenazine-treated (FLU) female $(n=6)$ and male $(n=22)$ patients and for the comparison females $(n=40$ and males $(n=41)$. The 1 and $\mathrm{r}$ hippocampus represent the ROIs also called medial temporal cortex as they contain both hippocampus and parahippocampus. Percentage differences (\% Diff) for CLOZ and FLU are calculated as $($ CLOZ-NC) $\times 100 /$ NC and $(F L U-N C) \times 100 / N C$, respectively. The statistical significance of differences between groups for the hippocampus, caudate, anterior putamen, and posterior putamen were calculated on the basis of least significant differences (LSD) of repeated measures analyses of variance with SEX and DRUG as the two between-groups factors and the left versus right region as the within-group factor. Cingulate values were calculated on the basis of a two-way ANOVA with SEX and DRUG as the factors. Using LSD, female versus male (F vs. M) significance was determined for the three groups, CLOZ, FLU, and NC., and the significance of CLOZ versus NC and FLU versus NC for males and females. All calculations were performed with CSS-Statistica@.

hypothesis rests on finding differences between the regional metabolic patterns of patients treated with neuroleptic medications and controls that are at least as great as those pre-existing and finding alterations in metabolism in regions either without pre-existing abnormalities or else in the direction of making any preexisting abnormality more severe. As discussed previously (Cohen et al. 1997), the data that established the above findings in men, contradicted the normalization hypothesis, but was consistent with the compensation hypothesis. The current data in women are equally consistent with the compensation hypothesis.

Compared to same sex controls, women, as with men with schizophrenia receiving neuroleptics, have a dramatically altered pattern of glucose metabolic rates while performing CPT. Furthermore, the altered patterns resulting from fluphenazine treatment resembles that of clozapine treatment, and both resemble those patterns found in men (Table 2). Where the findings in men and women are the same, no further delineation is necessary, because the significance of the decreases in the frontal cortex and increases in the basal ganglia and medial and temporal lobes with respect to the above predictions have been discussed (Cohen et al. 1997, 1988b).

Rather, our attention must be turned toward the few regional differences that exist between men and women 
receiving neuroleptic treatment for evidence that would be inconsistent with the compensation hypothesis. In women, but not in men, clozapine is equally as effective in increasing basal ganglia metabolism as fluphenazine, and both clozapine and fluphenazine decrease cingulate metabolism. Because it is unlikely that the schizophrenic patients we have studied while performing CPT have abnormally low basal ganglia or abnormally elevated cingulate metabolism before treatment (see discussion in Cohen et al. 1997 and Cohen et al. 1998; Kotrla and Weinberger 1995; Tamminga et al. 1992; Early et al. 1987), these sex differences would seem to strengthen the compensation hypothesis.

\section{Possible Causes of the Sex-Specific Response to Neuroleptics}

Several different possibilities have been put forward to explain sex differences in responses to neuroleptics. These have included sex differences in premorbid history, social adjustment, obstetric complications, and perinatal factors, symptom expression, and plasma levels of drug (Goldstein 1995; Haas and Castle 1997; Seeman 1995; Szymanski 1996). With respect to the latter factor, female subjects have been reported to have higher neuroleptic levels than males while receiving fluphenazine decanoate (Simpson et al. 1990) and clozapine (Szymanski et al. 1995), and to have higher prolactin and homovanillic acid levels (Szymanski et al. 1995; Bowers et al. 1984; Meltzer et al. 1983). Three facts, however, lessen the likelihood that pharmacokinetic factors alone underlie the PET differences observed. First, the statistically significant differences found are regionally selective. Second, there is a qualitative, not just a quantitative difference between the men and women, with respect to at least one of the differences; that is, the cingulate in the fluphenazine-treated patients. Third, the two regions, the cingulate and basal ganglia, that respond differentially in men and women, are two of the three regions found to have different metabolic rates in normal men and women performing CPT (Andreason et al. 1994).

Thus, the most parsimonious explanation is to posit that those factors that contribute to the different metabolic rates in the cingulate and basal ganglia in normal women and men (Gur et al. 1995; Andreason et al. 1994;) also lead to the differences in the regional metabolic patterns that we observe between the female and male schizophrenic patients receiving neuroleptics. For example, sex differences in regional neurotransmitter modulation could be the basis of both the regional metabolic differences observed between normal men and women as well as the localized differential metabolic responses of male and female schizophrenic patients receiving neuroleptics.

Although many neurotransmitter systems could be involved, the dopamine and serotonin systems are cer- tainly two of the obvious candidates, because significant evidence has accumulated for gender differences in both of these systems (Nishizawa et al. 1997; Janowsky et al. 1996; Di Paolo 1994; Konradi et al. 1992; Hafner et al. 1991; Arato et al. 1991; Carlsson and Carlsson 1988) as well as for their involvement in the response to neuroleptics (Goyer et al. 1996; Kahn and Van Praag 1996; Pickar 1995; Meltzer 1989;). Consistent with this idea that drugs affecting specific neurotransmitter systems may have differential gender effects is the previous observation of a gender difference in the regional metabolic responses to $\alpha_{2}$-adrenoreceptor blockade (Schmidt et al. 1997).

It is also of some interest that within the basal ganglia, the largest differences between the male and female response to clozapine treatment is on the left side. Whereas the female response is symmetric, the increase in the metabolic rate of the basal ganglia in the males was considerably larger on the right side. That we observed changes that were larger on the right than on the left side of the basal ganglia in males (Cohen et al. 1997) is consistent with a previous all-male PET study of neuroleptics (Buchsbaum et al. 1992b). In contrast to the right-sided basal ganglia asymmetry in neuroleptictreated patients, our own study (Cohen et al. 1998) and two other studies of either all-male or predominantly all-male patients (Buchsbaum et al. 1987; Early et al. 1987), not receiving neuroleptic medication, have suggested a left greater than right asymmetry in metabolic rates in the putamen. The basis of the underlying asymmetries in blood flow and metabolic rates in the basal ganglia of males may rest with asymmetries in the dopamine system. For example, a left lateralized asymmetry in the accumulation of SPECT tracers that bind to striatal $\mathrm{D}_{2}$ dopamine receptors have been observed in male, but not female, patients with schizophrenia (Schroder et al. 1997; Acton et al. 1997; Pilowsky et al. 1994).

Because the sex differences in metabolic responses are in the cingulate and basal ganglia, regions that receive significant dopamine and serotonin input and are implicated in the etiology and the treatment of schizophrenia (Gray 1998; Wyatt et al. 1995; Carpenter et al. 1993; Benes et al. 1992; Buchsbaum et al. 1992a; Davis et al. 1991; Grace 1991), these differences are likely to have implications for the differences in gender response to neuroleptics and suggest the importance of studying gender and steroid hormone effects on in vivo indices of regional dopamine and serotonin in schizophrenia.

\section{REFERENCES}

Acton PD, Pilowsky LS, Costa DC, Ell PJ (1997): Multivariate cluster analysis of dynamic iodine-123 iodobenzamide 
SPET dopamine D2 receptor images in schizophrenia. Eur J Nucl Med 24:111-118

American Psychiatric Association (APA) (1987): Diagnostic and Statistical Manual of Mental Disorders, 3rd Ed., Revised. Washington, DC, American Psychiatric Press

Andreason PJ, Zametkin AJ, Guo AC, Baldwin P, Cohen RM (1994): Gender-related differences in regional cerebral glucose metabolism in normal volunteers. Psychiat Res 51:175-183

Arato M, Frecska E, Tekes KEA (1991): Serotonergic interhemispheric asymmetry: Gender difference in the orbital cortex. Acta Psych Scand 84:110-111

Benes RM, Vincent SL, Alsterberg G, Bird ED, SanGiovanni JP (1992): Increased GABA-A receptor binding in superficial layers of cingulate cortex in schizophrenics. J Neurosci 12:924-929

Bowers, MB, Swigar, ME, Jatlow PI, Goicoechea, N (1984): Plasma catecholamine metabolites and early response to haloperidol. J Clin Psychiat 45:248-251

Brooks RA (1982): Alternative formula for glucose utilization using labeled deoxyglucose. J Nucl Med 23:538-539

Buchsbaum MS, Haier RJ, Potkin SG, Nuechterlein K, Bracha S, Jerabek P, Trenary M, Tafalla R, Reynolds C, Bunney WE (1992a): Frontostriatal disorder of cerebral metabolism in never-medicated schizophrenics. Arch Gen Psychiat 49:935-942

Buchsbaum MS, Potkin SG, Marshall JF, Lotterberg S, Teng C, Heh C, Tafalla R, Reynolds C, Abel L, Plon L, Bunney WE (1992b): Effects of clozapine and thiothixene on glucose metabolic rate in schizophrenia. Neuropsychopharmacology 6:155-163

Buchsbaum MS, Wu JC, DeLisi LE, Holcomb HH, Hazlett E, Cooper-Langston KRK (1987): Positron emission tomography studies of basal ganglia and somatosensory cortex neuroleptic drug effects: Differences between normal controls and schizophrenic patients. Biol Psychiat 22:479-494

Bunney WEJ, Hamburg DA (1963): Methods for reliable longitudinal observation of behavior. Arch Gen Psycht 9:280-294

Carlsson M, Carlsson A (1988): A regional study of sex differences in rat brain serotonin. Prog Neuropsychopharmacol Biol Psychiat 12:53-61

Carpenter WTJ, Buchanan RW, Kirkpatrick B, Tamminga C, Wood F (1993): Strong inference, theory testing, and the neuroanatomy of schizophrenia. Arch Gen Psychiat 50:825-831

Cohen RM, Nordahl TE, Semple WE, Andreason P, Litman RE, Pickar D (1997): The brain metabolic patterns of clozapine- and fluphenazine-treated schizophrenic patients during a continuous performance task. Arch Gen Psychiat 54:481-486

Cohen RM, Nordahl TE, Semple WE, Andreason P, Pickar D (1998): Abnormalities in the distributed network of sustained attention predict neuroleptic treatment response in schizophrenia. Neuropsychopharmacology 19:36-47

Cohen RM, Semple WE, Gross M, King AC, Nordahl TE (1992): The metabolic brain pattern of sustained auditory discrimination. Exp Brain Res 92:165-172

Cohen RM, Semple WE, Gross M, Holcomb HH, Dowling
MS, Nordahl TE (1988a): Functional localization of sustained attention: Comparison to sensory stimulation in the absence of instruction. Neuropsychiat, Neuropsychol, Behav Neurol 1:3-20

Cohen RM, Semple WE, Gross M, Nodahl TE, Holcomb HH, Dowling MS, Pickar D (1988b): The effect of neuroleptics on dysfunction in a prefrontal substrate of sustained attention in schizophrenia. Life Sci 43:1141-1150

Davis KL, Kahn RS, Ko G, Davidson M (1991): Dopamine in schizophrenia: A review and reconceptualization. Am J Psychiat 148:1474-1486

Di Paolo T (1994): Modulation of brain dopamine transmission by sex steroids. Rev Neurosci 5:27-42

Early TS, Reiman EM, Raichle ME, Spitznagel EL (1987): Left globus pallidus abnormality in never-medicated patients with schizophrenia. Proc Natl Acad Sci USA 84:561-563

Goldstein JM (1995): The impact of gender on understanding the epidemiology of schizophrenia. In Seeman MV (ed), Gender and Psychophathology. Washington, DC, American Psychiatric Press. pp 159-199

Goyer PF, Berridge MS, Morris ED, Semple WE, ComptonToth BA, Schulz SC, Wong DF, Miraldi F, Hy M (1996): PET measurement of neuroreceptor occupancy by typical and atypical neuroleptics. J Nucl Med 37:1122-1127

Grace AA (1991): Phasic versus tonic dopamine release and the modulation of dopamine system responsivity: A hypothesis for the etiology of schizophrenia. Neuroscience 41:1-24

Gray JA (1998): Abnormal contents of consciousness: The transition from automatic to controlled processing. Adv Neurol 77:195-208

Gur CR, Harper-Mozley L, Mozley DP, Resnick SM, Karp JS, Alavi A, Arnold SE, Gur RE (1995): Sex differences in regional cerebral glucose metabolism during a resting state. Science 267:528-531

Haas GL, Castle DJ (1997): Sex differences in schizophrenia. In Keshavan MS, Murray RM (eds), Neurodevelopment \& Adult psychopathology. Cambridge, UK, Cambridge University Press, pp 155-177

Hafner H, Behrens S, De Vry J, Gataz WF (1991): An animal model for the effects of estradiol on dopamine-mediated behavior: Implications for sex differences in schizophrenia. Psychiat Res 38:125-134

Janowsky DS, Halbreich U, Rausch J (1996): Association among ovarian hormones, other hormones, emotional disorders, and neurotransmitters. In Jensvold MF, Halbreich U, Hamilton JA (eds), Psychopharmacology and Women: Sex, Gender, and Hormones. Washington, DC, American Psychiatric Press, pp 85-106

Kahn RS, Van Praag HM (1996): Dopamine, serotonin, and their interactions in schizophrenia. In Kane JM, Moller H-J, Awouters F (eds), Serotonin in Antipsychotic Treatment: Mechanisms and Clinical Practice. New York, Marcel Dekker, pp 131-152

Konradi C, Kornhuber J, Sofic E, Heckers S, Riederer P, Beckmann H (1992): Variations of monoamines and their metabolites in the human brain putamen. Brain Res 579:285-290 
Kotrla KJ, Weinberger DR (1995): Brain imaging in schizophrenia. Ann Rev Med 36:1275-1281

Matsui T, Hirano A (1978): An Atlas of the Human Brain for Computerized Tomography. New York, Igaku-Shoin Medical

Meltzer HY (1989): Clinical studies on the mechanism of action of clozapine: The dopamine-serotonin hypothesis of schizophrenia. Psychopharmacology 99:S18-S27

Meltzer HY, Busch D, Fang V (1983): Serum neuroleptic and prolactin levels in schizophrenic patients and clinical response. Psychiat Res 9:271-283

Nishizawa S, Benkelfat C, Young SN, Leyton M, Mzengeza S, De Montigny C, Blier P, Diksic M (1997): Differences between males and females in rates of serotonin synthesis in human brain. Proc Natl Acad Sci USA 94:65176522

Overall JE, Gorham DE (1961): The brief psychiatric rating scale. Psychol Res 10:799-812

Phelps ME, Huang S-C, Hoffman EJ, Selin C, Sokoloff L, Kuhl DE (1979): Tomographic measurement of local cerebral glucose metabolic rate in humans with [F-18]1fluoro-2-deoxy-D-glucose: Validation of method. Ann Neurol 6:371-388

Pickar D (1995): Prospects for pharmacotherapy of schizophrenia. Lancet 345: 557-562

Pickar D, Owen RR, Litman RE, Konicki PE, Gutierrez R, Rapaport MH (1992): Clinical and biologic response to clozapine in patients with schizophrenia: Crossover comparison with fluphenazine. Arch Gen Psychiat 49:345-353

Pilowsky LS, Costa DC, Ell PJ, Verhoff NPLG, Murray RM, Kerwin RW (1994): D2 dopamine receptor binding in the basal ganglia of antipsychotic-free schizophrenic patients. An 123I-IBZM single photon emission computerized tomography study. Br J Psych 164:16-26

Pinals D, Malhotra AK, Missar CD, Pickar D, Breier A (1996): Lack of gender differences in neuroleptic response in patients with schizophrenia. Schizophr Res 22:215-222

Schmidt ME, Matochik JA, Goldstein DS, Schouten JL, Zametkin AJ, Potter WZ (1997): Gender differences in brain metabolic and plasma catecholamine responses to alpha 2-adenoceptor blockade. Neuropsychopharmacology 16:298-310
Schroder J, Bubeck B, Silvestri S, Demisch S, Sauer H (1997): Gender differences in D2 dopamine receptor binding in drug-naive patients with schizophrenia: An [I-123]iodobenzamide single photon emission computed tomography study. Psychiat Res: Neuroim Sect 75:115-12

Seeman MV (1995): Gender differences in treatment response to schizophrenia. In Seeman MV (ed), Gender and Psychopathology. Washington, DC, American Psychiatric Press, pp 227-268

Semple WE, Johnson JL, Cohen R (1993): Reliability in positron emission tomography. In London ED (ed), Imaging Drug Action in the Brain. Boca Raton,FL, CRC Press, pp 297-316

Simpson GM, Yadalam KG, Levenson DF, Stephanos MJ, Lo ES, Cooper TB (1990): Single-dose phamacokinetics of fluphenazine after fluphenazine decanoate administration. J Clin Psychopharmacol 10:417-421

Sokoloff L, Reivich M, Kennedy C, DesRosiers MH, Patlak CS, Pettigrew KD, Sakurada O, Shinohara M (1977): The [14-C]deoxyglucose method for the determination of local cerebral glucose utilization: Theory, procedure, and normal values in the conscious and anesthetized albino rat. J Neurochem 28:897-896

Szymanski S (1996): Sex differences in schizophrenia. In Jensvold MF, Halbreich U, Hamilton JA (eds), Psychopharmacology and Women: Sex, Gender, and Hormones. Washington, DC, American Psychiatric Association Press, pp 287-297

Szymanski S, Lieberman JA, Alvier JM, Mayerhoff D, Loebel A, Geisler S, Chakos M, Koreen A, Jody D, Kane J, Woener M, Cooper T (1995): Gender differences in onset of illness, treatment response, course and biological indexes in first-episode schizophenic patients. Am J Psychiat 152:698-703

Tamminga CA, Thakur, G.K., Buchanan R, Kirkpatrick B, Alphs LD, Chase TN, Carpenter WT (1992): Limbic system abnormalities identified in schizophrenia using positron emission tomography with fluorodeoxyglucose and neocortical alterations with deficit syndrome. Arch Gen Psychiat 49:522-530

Wyatt RJ, Karoum F, Casanova MF (1995): Decreased DOPAC in the anterior cingulate cortex of individuals with schizophrenia. Biol Psych 38:4-12 